\title{
Corroded Device
}

National Cancer Institute

\section{Source}

National Cancer Institute. Corroded Device. NCI Thesaurus. Code C63263.

Problem associated with the chemical or electrochemical reaction between materials, usually a metal and its environment that produces a deterioration of the metal and its properties. 